\title{
Percutaneous Transpedicular Lumber Fixation
}

Mohammed salem mohammed ahmed ${ }^{1, *}$ MSc, shehab M. Elkhadrawy ${ }^{1}$ MD, Mohammed Elsayed saleh ${ }^{1}$ MD

*Corresponding Author:

Mohammed salem mohammed ahmed Muhammadsalem9191@gmail.com

Received for publication July 27, 2020; Accepted October 3, 2020; Published online October 3, 2020.

Copyright 2020 The Authors published by Al-Azhar University, Faculty of Medicine, Cairo, Egypt. All rights reserved. This an openaccess article distributed under the legal terms, where it is permissible to download and share the work provided it is properly cited. The work cannot be changed in anyway or used commercially.

doi: 10.21608/aimj.2020.37368.1285

${ }^{1}$ Neurosurgery Department, Faculty of Medicine, Al-Azhar University, Cairo, Egypt.

Disclosure: The authors have no financial interest to declare in relation to the content of this article. The Article Processing Charge was paid for by the authors.

Authorship: All authors have a substantial contribution to the article.

\begin{abstract}
Background: Posterior Pedicle screw fixation has step by step become popular to thoracolumbar fracture management. Since Roy-Camille et al used application of plates with pedicle screws for thoracolumbar fractures in 1963.
\end{abstract}

Aim of work: to evaluate the percutaneous transpedicular fixation for management of lumbar fractures.

Patient and Methods: This research was done on 20 patients presented by lumbar spine fractures; they were treated with percutaneous transpedicular fixation and stabilization at Al-Azhar University hospitals from June 2019 to February 2020.All patients were without neurological deficits theywere fixed either one level above and one level below or two levels above and two levels below the fractured vertebra.

Results: Clinical and functional outcomes are preferable or comparable to conventional open procedures. The key disadvantages of this procedure are the steep learning curve and radiation exposure to both doctors, nurses and surly patients, which may be reduced as much as possible by using the new 3D CT screw insertion process.

Conclusion: Percutaneous transpedicularspine fixation is a secure technique that follows the same principles as open procedures, allowing the surgeon to conduct biomechanically strong internal spinal fixation with minimal tissue damage, and is a suitable choice for the treatment of unstable thoracolimber fractures with no neurological deficit. This has the benefit of short-time surgery, no loss of blood, almost no muscle damage results in less postoperative pain than conventional open procedures, short hospitalization, early mobilization, a quicker return to work and a low risk of complications.

Keywords: percutaneous transpedicular lumber fixation; segment fixation; lumbar fracture

\section{INTRODUCTION}

The thoracolumbar fractureis one of the highest common spine fractures and more than 160,000 cases of injury occurred last year. ${ }^{1}$

A significant percentage of thoracolumbar fractures happens at levels T11 to L2, which is weak facing external forces. ${ }^{2}$

The choice of treatment procedures, including conservative management and surgical treatment, depends on the particular circumstances of the fractures.Surgical treatment approaches in patients with thoracolumbar fractures often achieve reasonably better clinical results compared to conservative care, such as rest in bed and immobilization. ${ }^{3}$
Over the last 20 years, interest in spine fractures has grown when new and more advancedsurgical treatment options have been developed.. A large number of publications detailing different surgical procedures for the reduction and fixation of thoracolumbar fractures, accompanied by discussions between the authors, have not led to a general consensus on optimal treatment. ${ }^{4}$

Traditional open spine surgery has many limitations identified, including significant blood loss, risk of infection, and muscle pain postoperative. Paravertebral muscle dissection required in internal spine fixation may cause excessive denervation, increased intramuscular tension, ischemia, necrosis and revascularization, resulting in postoperativemuscle atrophy and scarring, mostly associated with extended postoperative pain and disability. $^{5}$

Percutaneous transpedicular fixation has recently been introduced as an effective procedure for the treatment of thoracolumbar fractures, with the goal of reducing soft tissue injury and perioperative morbidity. ${ }^{6}$ 
Percutaneous transpedicular fixation was first introduced by Magerl whom used an external fixator and then Mathews \& Long first described and achieved entirely percutaneous lumbar pediclefixation techniques in which plates were utilized as longitudinal connectors. Lowery \& Kulkarni ${ }^{7}$ Consequently described an analogous technique where rods were placed, although the latter authors observed a high rate of success, Mathews \& Long noted a large non-union rate.

In all of these previous procedures, the longitudinal connectors were located either externally or superficially below the skin. It has many possible drawbacks, first; the superficial connectors is irritating and needs removal, second; longer screws (and therefore longer moment arms) are needed generating a less efficient biomechanical stabilization than that produced by the traditional system for pedicle fixation leading to an increased risk for implant failure. ${ }^{7}$

To overcome the complication of both conventional posterior spinal fixation and the complication of superficially placedhardware, other systems of percutaneous spine fixation have been developed in which the hardware is placed in close contact to the bone allowing fixation comparable to open positioning of screws. These systems namely are (SEXTANT), path finder \& (World Spine Highlight W.S.H.) systems in which rods \& plates respectively are used as longitudinal connector. ${ }^{\mathbf{8}}$

\section{PATIENT AND MATERIALS}

This is prospective and retrospective study that was conducted on 20 patients with lumbar fractures all of them were treated by percutaneous pedicle screw fixation in Al-Azhar university hospital from 6/2019 to $1 / 2020$. All of them were neurological free.

The patients were thoroughly examined by these specialities, there vital states (airway, breathing \& circulation) were well assessed and any dysfunction was well managed by the team. Once the patient is stabilized haemo-dynamically a diagnostic work up was done, as regard to patient with suspected spine injury conventional $\mathrm{x}$ - ray radiography, computed tomography and MRI were done to identify level of injury and type of fracture. Once the fracture is identified and classified, we prepare a treatment plan based on the fracture pattern, the severity of injury and the patients' overall condition.

The follow-up period was 6 months, Patients were reviewed at 2 weeks postoperatively for removal of stitches then monthly for 3 successive months' then after 3 months to be evaluatedclinicallyand radiologicallythis program is recommended for all patients with the exception of patients who have associated fracture.

Preoperative evaluation Preoperative clinical and radiological findings:

Each patient is evaluated clinically; radiologically and by other preoperative laboratory investigations to confirm fitness for general anesthesia.

Clinical evaluation:Personal history including: Name, Age, Sex, Occupation, Address and Special
habits.History of trauma including: Site, Mode, Time elapsed till presentation and Severity.Neurological disorders including: Sensory, Motor and sphincteric disorders.History of chest, cardiac or general health problems that may hinder anesthesia.

Examination:General examination including:Evaluation of hemodynamic state of the patient (Pulse, blood pressure, temperature and respiratory rate).Head, chest and abdomen for life threatening injuries.Examination of extremities for associated injuries.Spine examination:Inspection of the back and other related regions.Palpation of the spine.Evaluation of deformity especially in old cases.Neurological evaluation:ASensory examination:Superficial sensation including: Pain, Touch, Temperature, Perianal sensation.Deep sensation: Joint sensation: Sense of joint motion, sense of position and deep pressure sense.B-Motor examination for Muscle power. Reflexes: Superficial: Abdominal reflexes Planter reflex Deep : Knee reflex. Ankle reflex.Radiological evaluation: plain X- ray, CT and MRI.

The study included cases of lumber fractures without neurological deficit.While cases of lumber fractures associated with neurological deficit and cord compression were excluded from the study.

After hospital admission to the following were done:Full lap. was done to the patientThe patient was instructed not to sit in bed.Anti-thrombotic treatment was started.No catheterization was used; all patients were neurologically free.Oral analgesics administrated with mild pain and parentral analgesics withsevere pain and poly trauma patients were administrated.The surgical procedure and postoperative management were discussed with patient and his relative and the surgeon answered any question the patient had in mind about the operation.The aim of surgery was to stabilize the spine using a percutaneous pedicle screws.

Preoperative preparation and positioning:All of the patients were given prophylactic antibiotic $\left(3^{\text {rd }}\right.$ generation Cephalosporin) 1gm before induction of anesthesia. The patients were positioned prone, under general anesthesia on a radiolucent table with a small towel under chest of the patient with hyper extension of the leg.

The skin incision was determined using a radiographic marker after taking a C-Arm shot to determine the affected and working levels

Procedure for Percutaneous Pedicle Screw Fixation:

Skin incision and entry point:The entry points of the skin are positioned lateral to the prdicle point 1 to 2 $\mathrm{cm}$ to provide a trajectory which follows the lateral-tomedial curvature of the pedicle.t 1rNeighboring entry points are at a large distance from each other about 1.5 cm separate incisions ${ }^{(9)}$.

Placing Jamshidi needle through the pedicle:The needle pushes through the skin until the tip of the needle get in touch with junction of the facet and the transverse process with fluoroscopic guidance. The Jamshidi needle then pushed in the lateral aspect of the pedicle. This is called the "3 o-clock" position on the RT side and the ' 9 o-clock' position on the LT side. Advance the Jamshidi needle in the pedicle around 20to $25 \mathrm{~mm}$, 
ensuring that the needle stays lateral to the medial wall of pedicle. The Jamshidi needle is now in the vertebral body and thus secured without the risk of a medial pedicle split. Placing all the needles before proceeding to the next step makes it easier to place the needles on the second pedicle. Even, as we insert the needle on the opposite side, the vision is only minimally interrupted by the initial screw. ${ }^{(9)}$.

Insertion of K-wires: Put a K-wire down inside the Jamshidi needle.

Dilatation of muscles:Sequential dilators are placed over the guide wire to extend the path through the muscle and this technique provides the direction of the appropriate space and prevents tissue damage and then places a pedicle tap down the path of the K-wire ${ }^{(9)}$.

Placement of the screw: After the last dilator has been removed, the entire screw-extender assembly is placed over the K-wire and the screw is inserted into the pedicle under fluoroscopic guidance. When the screw has entered the vertebral body, the wire is removed to prevent the assembly from continuing advancement. Therefore the other screws are inserted at the same depth $^{(9)}$

Mesurement and insertion of the rod: Post-operative care:All patients were neurologically tested before leaving the operating room after recovery,all patients were given $3^{\text {rd }}$ generation Cephalosporin (Cefotaxime 1 gm every 12 hours)for one week and non-steroidal antiinflammatory drugs was given according to patient tolerance.

All patients wore lumbar brace, for 2-3 weeks, then the brace was discarded and the patients were advised to ambulate immediate post-op But bending or twisting of the waist and raising more than $5 \mathrm{lb}$ is generally not allowed for 3 months. Limitations, such as preventing over-exercise from climbing stairs, pushing or pulling movements, extended setting and extended standing, all of these behaviors are usually limited to 3-6 months. Postop plain X-ray and CT were done to assess mid sagittal diameter of neural canal and screws position.All patients were instructed to wear their brace during movement and take it off before going to sleep.Patients with only spine fracture were released from hospital on the second day following surgery.The patient's first return to the outpatient clinic was 7 days following discharge, and the follow-up during that time focused on wound assessment, patient reassurance and a shift in the type of analgesics according to the patient's complaint.This program is recommended for all patients except in patients who have associated fracture calcaneus.

Postoperative evaluation: The patients were reviewed at 2 weeks postoperatively for removal of stitches, clinical and neurological examination.Follow up:Follow up was done at 6 weeks, $3 \& 6$ months. The following items were evaluated at each visit:Clinical evaluation included neurological examination.Back pain, movement of the spine,return to work, Satisfaction andcomplications. Radiological evaluation where Plain x-rays and CT were done if needed.

Statistical analysis: The data recorded was analyzed using the Social Sciences Statistical Package, version
20.0 (SPSS Inc., Chicago, Illinois, USA). Quantitative data were presented as mean \pm standard deviation ( SD). Qualitative data was expressed as a frequency and percentage of data.

The following tests were done:Chi-square $\left(\mathrm{x}^{2}\right)$ test of significance was used in order to compare proportions between qualitative parameters.Paired sample t-test of significance was used when comparing between related sample.The confidence interval was set to $95 \%$ and the margin of error accepted was set to $5 \%$. So, the p-value was considered significant as the following:Probability (P-value)P-value $<0.05$ was considered significant.

\section{RESULTS}

\begin{tabular}{|c|c|}
\hline Demographic data & Total $(n=20)$ \\
\hline \multicolumn{2}{|l|}{ Age (years) } \\
\hline$<25$ years & $5(25.0 \%)$ \\
\hline $25-<30$ years & $6(30.0 \%)$ \\
\hline $30-35$ years & $4(20.0 \%)$ \\
\hline$>35$ years & $5(25.0 \%)$ \\
\hline Range & $17-51$ \\
\hline$M e a n \pm S D$ & $31.00 \pm 9.97$ \\
\hline \multicolumn{2}{|l|}{ Sex } \\
\hline Female & $9(45.0 \%)$ \\
\hline Male & $11(55.0 \%)$ \\
\hline
\end{tabular}

Table 1: Distribution of percutaneous transpedicular fixation cases according to their demographic data regarding gender and age $(n=20)$.

This table shows that the $<25$ years 5 (25.0\%), $25-<30$ years $6(30.0 \%), 30-35$ years $4(20.0 \%)$ and $>35$ years 5 (25.0\%), also ranged $17-51$ with mean $31.00 \pm 9.97$ of age (years), while female (45\%) and male (55\%) of sex.

\begin{tabular}{|c|c|}
\hline Injury & Total (n=20) \\
\hline Level of injury & \\
\hline L1 & $7(35.0 \%)$ \\
\hline L2 & $5(25.0 \%)$ \\
\hline L3 & $2(10.0 \%)$ \\
\hline L4 pars & $4(20.0 \%)$ \\
\hline L5 & $1(5.0 \%)$ \\
\hline L5 pars & $1(5.0 \%)$ \\
\hline Mechanism of injury & \\
\hline FFH & $9(45.0 \%)$ \\
\hline RTA & $6(30.0 \%)$ \\
\hline Twiting Rotation & $5(25.0 \%)$ \\
\hline
\end{tabular}

Table 2: Distribution of percutaneous transpedicular fixation cases according to their injury data regarding level of injury and mechanism of injury $(n=20)$.

This table shows that the L1 7 (35.0\%), L2 5 (25.0\%), L3 2 (10.0\%), L4 pars 4 (20.0\%), L5 1 (5.0\%) and L5 pars $1(5.0 \%)$ of level of injury, whileFFH $9(45.0 \%)$, RTA 6 (30.0\%) and Twiting Rotation 5 (25.0\%) of Mechanism of injury. 


\begin{tabular}{|c|c|}
\hline Duration of surgery (min) & Total $(\mathbf{n}=\mathbf{2 0})$ \\
\hline$<70$ min. & $3(15.0 \%)$ \\
\hline$\geq 70-80$ min. & $6(30.0 \%)$ \\
\hline$>80-100$ min. & $9(45.0 \%)$ \\
\hline$>100$ min. & $2(10.0 \%)$ \\
\hline Range & $60-120$ \\
\hline Mean $\pm S D$ & $80.50 \pm 15.97$ \\
\hline
\end{tabular}

Table 3: Distribution of percutaneous transpedicular fixation cases according to their duration of surgery $(n=20)$.

This table shows that the $<70$ min. $3(15.0 \%), \geq 70-80$ min. 6 (30.0\%), >80-100 min. $9(45.0 \%)$ and $>100$ min. 2 (10.0\%), also ranged 60-120 with mean $80.50 \pm 15.97$ of duration of surgery.

\begin{tabular}{|c|c|}
\hline Blood Loss (cc) & Total (n=20) \\
\hline$<100 \mathrm{cc}$ & $6(30.0 \%)$ \\
\hline $100 \mathrm{cc}$ & $9(45.0 \%)$ \\
\hline$>100 \mathrm{cc}$ & $15(75.0 \%)$ \\
\hline Range & $70-250$ \\
\hline Mean $\pm S D$ & $105.00 \pm 39.27$ \\
\hline
\end{tabular}

Table 4: Distribution of percutaneous transpedicular fixation cases according to their blood loss $(n=20)$.

This table shows that the <100cc 6 (30.0\%), 100cc 9 (45.0\%) and >100cc 15 (75.0\%), also ranged 70-250 with mean $105.00 \pm 39.27$ of blood loss (cc),

\begin{tabular}{|c|c|}
\hline Radiation exposure (min) & Total (n=20) \\
\hline <3min. & $4(20.0 \%)$ \\
\hline At 3min. & $8(40.0 \%)$ \\
\hline 33-5min. & $8(40.0 \%)$ \\
\hline Range & $2.5-5$ \\
\hline Mean $\pm S D$ & $3.25 \pm 0.64$ \\
\hline
\end{tabular}

Table 5: Distribution of percutaneous transpedicular fixation cases according to their radiation exposure $(n=20)$.

This table shows that the $<3 \min .4$ (20.0\%), At 3min. $8(40.0 \%)$ and $>3-5 \mathrm{~min} .8(40.0 \%)$, also ranged $2.5-5$ with mean $3.25 \pm 0.64$ of radiation exposure.

\begin{tabular}{|c|c|}
\hline Hospital stay (days) & Total $(\mathbf{n}=\mathbf{2 0})$ \\
\hline At 2min. & $13(65.0 \%)$ \\
\hline At 3min. & $4(20.0 \%)$ \\
\hline$>3-5 m i n$. & $3(15.0 \%)$ \\
\hline Range & $2-5$ \\
\hline Mean $\pm S D$ & $2.60 \pm 0.99$ \\
\hline
\end{tabular}

Table 7: Distribution of percutaneous transpedicular fixation cases according to their hospital stay $(n=20)$.

This table shows that the At 2min. 13 (65.0\%), At 3min. 4 (20.0\%) and $>3-5 \mathrm{~min} .3$ (15.0\%), also ranged 2-5 with mean $2.60 \pm 0.99$ of hospital stay (days).

\begin{tabular}{|c|c|}
\hline Screw position & Total (n=86) \\
\hline Good & $81(94.2 \%)$ \\
\hline Lateral & $4(4.7 \%)$ \\
\hline Medial & $1(1.2 \%)$ \\
\hline
\end{tabular}

Table 6: Distribution of percutaneous transpedicular fixation cases according to their screw position $(\mathrm{n}=86)$.

This table shows that the Good 81 (94.2\%), Medial 4 (4.7\%) and Lateral 1 (1.2\%) of Screw position.

\begin{tabular}{|c|c|}
\hline Back pain & Total (n=20) \\
\hline Pre-operative & \\
\hline P4 & $16(80.0 \%)$ \\
\hline P5 & $4(20.0 \%)$ \\
\hline Post-operative at 6 months & \\
\hline P1 & $15(75.0 \%)$ \\
\hline P2 & $5(25.0 \%)$ \\
\hline Chi-square test & $\mathbf{3 8 . 6 8 1}$ \\
\hline p-value & $<\mathbf{0 . 0 0 1}^{* *}$ \\
\hline
\end{tabular}

Table 8: Comparison between pre-operative and postoperative at 6 months according to back pain $(n=20)$.

This table shows statistically significant decrease back pain in post-operative at 6months compared to preoperative according to back pain with p-value $<0.001$ highly significant.

\begin{tabular}{|c|c|c|c|c|c|}
\hline \multirow[b]{2}{*}{ Back pain } & \multirow[b]{2}{*}{ Range } & \multirow{2}{*}{$\begin{array}{c}\text { Mean } \\
\pm \text { SD }\end{array}$} & \multicolumn{3}{|c|}{ Paired Sample t-test } \\
\hline & & & $\begin{array}{l}\text { Mean } \\
\text { Diff. }\end{array}$ & t-test & $\begin{array}{c}\mathrm{p}- \\
\text { value }\end{array}$ \\
\hline Pre-operative & $4-5$ & $\begin{array}{c}4.20 \pm \\
0.41\end{array}$ & \multirow{2}{*}{2.95} & \multirow{2}{*}{6.39} & \multirow{2}{*}{$\begin{array}{c}<0 . \\
001 \\
* *\end{array}$} \\
\hline $\begin{array}{r}\text { Post-operative } \\
\text { at } 6 \text { months }\end{array}$ & $1-2$ & $\begin{array}{c}1.25 \pm \\
0.44\end{array}$ & & & \\
\hline
\end{tabular}

Table 9: Comparison between pre-operative and postoperative at 6 months according to mean of back pain $(n=20)$.

This table shows highly statistically significant decrease back pain in post-operative at 6months compared to pre-operative according to mean of back pain with p-value $<0.001$ highly significant.

\section{DISCUSSION}

Traditional open approach for thoracolumbar spine fixationrequires huge soft tissue dissection to show the bone structure of the spine and to connect the pedicle to the screw. Consecutively, paraspinal muscles are denervated and dissection leads to muscle and soft tissue ischemia, severe postoperative pain, lengthy recovery periods and possibly contributes to certain cases of failed fracture stabilization. ${ }^{10}$

This is a prospective and retrospective study of 20 patients started from June 2019 to February 2020. Nine patients were females $45 \%$ and eleven males $60 \%$; average age was 31 years (range from 17 to 51).

$\mathrm{Ni}$ et $\mathrm{al}^{11}$ reported thirty six consecutive patients underwent percutaneous fixation during the period from January 2003 to December 2006.

There were twenty-five men and eleven women aged between 19 and 58 years (average age was 43.2 years).

Palmisani et al. ${ }^{12}$ reported 51 successive patients with thoracolumbar fractures fixed with percutaneous screws from May 2005 to April 2008.

There were 17 female patients, 34 males, with an average age of 45 years (range 21 to 82).

Wang Hong-weiet al ${ }^{13}$ reported 38consecutive patients of thoracolumbar fractures 17 of them stabilized by Sextant percutaneous screws (13 men and 4 women).

In this study the mechanisms of injury were motor vehicle in Six patients (30\%), fall from height in nine 
patients (45\%) and twisting rotation injury (fracture pars without spondylolisthesis) in 5 patients (25\%).

One patient was fixed two levels above and two levels below and 19 patientswere fixed one level above and one level below.

Ni et $\mathrm{al}^{11}$ Stated that the injury cause involves a fall from height in 24 patients and a motor vehicle accident in 12 patients.

Palmisani et al. ${ }^{12}$ stated that the mechanism of injurywere a motor vehicle accident in 34 patients (66 $\%)$ and a fall from height in 17 patients (34\%).

Wang Hong-weiet al ${ }^{13}$ reported that the causes of injury were due to fall from height in 53 patients, motor car accident in 24 patients, falling from low height in 20 patients and a heavy object struck in 3 patients. The injury levels were T11 in twopatients, T12 in fourteen patients, L1 in sixty patients and L2 in twenty fourpatients.

In this study the average time of operation was 80.5 minutes (range 60 to $120 \mathrm{~min}$ ). Long time of operation was in early cases because we were at the beginning of the learning curve and we used to apply screws one by one that taking a lot of time later we started to apply 2 screws at the same time that make the time of surgery short.

Wild et al ${ }^{14}$ reported in percutaneousfixation that the mean operative time (47.0 min \pm 14.4 ) was lower than the traditional pedicle screw fixation technique ranging from 81 to $240 \mathrm{~min}$

Merom et al. ${ }^{(15)}$ Reported that with percutaneous shortsegment fixation, the operating period(73 to 85 minutes) was shorter than for traditional open fixation (78 to 102 minutes).

$\mathrm{Ni}$ et $\mathrm{al}^{11}$ recorded average operating time of 70 minutes for percutaneous short-segment fixation.

Wang Hong-weiet al. ${ }^{13}$ reported mean operating time was average of $78 \mathrm{~min}$ (ranging from $80 \mathrm{~min}$ to130 min).

In comparison to open surgeries $\mathrm{Ni}$ et $\mathrm{al}^{11}$ recordedoperative time of about $153 \mathrm{~min}(125$ - 205) in open pedicle screw fixation.

In our work the average intraoperative loss of blood was $105 \mathrm{~mL}$ (ranging from $70 \mathrm{~mL}$ to $250 \mathrm{~mL}$ ).

Wild et al. ${ }^{14}$ reported in non-randomized study with thoracolumbar fractures, lower blood loss (less than $10 \mathrm{ml}$ ) in percutaneous pedicle screw fixation than open surgery.

Wang Hongwei et $\mathrm{al}^{13}$ reported mean blood loss was $83.5 \pm 51.8$ (ranging from $20 \mathrm{ml}$ to200 ml)

$\mathrm{Ni}$ et $\mathrm{al}^{11}$ reportedblood loss (averaged $75 \mathrm{~mL}$ ) in percutaneous transpedicular fixation.

In comparison to open techniques Wild et $\mathrm{al}^{14}$ reported blood loss of 150 to $800 \mathrm{ml}$ with average $350 \mathrm{ml}$ in open pedicle screw fixation.

$\mathrm{Ni}$ et $\mathrm{al}^{11}$ reportedblood loss (averaged $75 \mathrm{~mL}$ ) in percutaneous pedicle screw fixation.
In this study the average radiation exposure was 3.25 min

Wild et al. ${ }^{14}$ recorded average radiation exposure was $5.7 \mathrm{~min}$.

Schmidt et al ${ }^{16}$ recorded average radiation exposure was $5.99 \mathrm{~min}$.

In our work The hospital stay for the patients averaged 2.6 days (range 2 to 5 days).

Wild et $\mathrm{al}^{14}$ reported in percutaneous transpedicularfixation, the mean length of hospital stay was 15 days \pm 4 days.

Wang Hong-weiet $\mathrm{al}^{13}$ recorded mean hospital stay was $11.1 \pm 3.8$ (ranging from 5 days to18days).

In comparison of open surgery wang bowen et $\mathrm{al}^{(17)}$ reported that hospital stay in open surgery versus percutaneouswas $20.7 \pm 5.2$ days and $9.4 \pm 3.2$ days respectively.

In this study we had 5 mal-placed screws. Four of them preached the lateral wall of the pedicle and one preached the medial wall of the pedicle but no canal encroachment or nerve injury.

In our work no major complications happened as nerve injury, Dural tear or serious postoperative infection.

The main drawback to this procedure is radiation exposure to both doctors, nurses and surly patients, which can reduce by inserting two screws and taking Xrays at the same timeand by using the new $3 \mathrm{D} C \mathrm{CT}$ navigation system.

Finally we can't ignore that the percutaneous systems are more expensive than traditional screws and also the surgical technique of percutaneous fixation of pedicles carries a high steep learning curve and mandates proper training before its routine usage.

wang bowen et $\mathrm{al}^{17}$ reported that one case in the percutaneous pedicle screw fixation group was recorded with wound infection, and no patient in the percutaneous pedicle screw fixation group was recorded with pseudarthrosis, recurrence, or apparent kyphosis.Patients with wound infection have been managed with surgical debridement in conjunction with antibiotic therapy.

$\mathrm{Ni}$ et $\mathrm{al}^{11}$ recorded that $6.7 \%$ of the 104 screws inserted had been misplaced, but there were no neurological problems. One patient with superficial infection out of 36 patients with percutaneous transpedicular fixation; the infection was treated only with antibiotics.

Wang Hong-Weiet $\mathrm{al}^{13}$ reported that there was no malposition screws in the percutaneous pediclescrew fixationgroupand also no intra operative or postoperative complications in this group.

\section{CONCLUSION}

Percutaneous transpedicularfixation is a secure technique that follows the same concepts as open procedures, allowing the surgeon to conduct biomechanically strong internal spinal fixation with minimal tissue damage, and is a suitable choice for the treatment of unstable thoracolimber fractures with no neurological deficit. oIt has the benefit of short-time of 
operation, minimal blood loss, little muscle damage actually results in lesser postoperative pain than traditional open techniques, short hospitalization, early mobilization, a quicker return to work and a low risk of complications.

\section{REFERENCES}

1. Alpantaki K, Bano A, Pasku D. Thoracolumbar burst fractures: a systematic review of management. Orthopedics 2010;33:422-9.

2. Wu Y, Chen $\mathrm{CH}$, Tsuang FY, Lin YC, Chiang CJ, Kuo YJ.The stability of long-segment and shortsegment fixation for treating severe burst fractures at the thoracolumbar junction in osteoporotic bone: A finite element analysis. PloS one. 2019 Feb 4;14(2):e0211676.

3. Verheyden AP, Spiegl UJ, Ekkerlein H, Gercek E, Hauck S, Josten C, Kandziora F, Katscher S, Kobbe P, Knop C, Lehmann W.Treatment of fractures of the thoracolumbar spine: recommendations of the spine section of the German Society for Orthopaedics and Trauma (DGOU). Global spine journal. 2018;8(2_suppl):34S-45S.

4. Walker CT, Xu DS, Godzik J, Turner JD, Uribe JS, Smith WD.Minimally invasive surgery for thoracolumbar spinal trauma. Annals of translational medicine. 2018 Mar;6(6).

5. Harris EB, Massey P, Lawrence J, et al. Percutaneous techniques for minimally invasive posterior lumbar fusion. Neurosurg Focus. 2008;25:E12.

6. Kocis J, Kelbl M, Kocis T, Návrat T.Percutaneous versus open pedicle screw fixation for treatment of type A thoracolumbar fractures. European Journal of Trauma and Emergency Surgery. 2020;46(1):147-52.

7. Mobbs RJ, Phan K.History of retractor technologies for percutaneous pedicle screw fixation systems. Orthopaedic surgery. 2016 Feb;8(1):3-10.

8. Tropiano P, Giorgi H, Faure A, Blondel B. Surgical techniques for lumbo-sacral fusion. Orthopaedics \& Traumatology: Surgery \& Research. 2017;103(1):S151-9.
9. Jack AS, Ramey WL, Oskouian RJ, Hart RA, Roh JS.Percutaneous Cortical Screw Fixation as a Method for Posterior Spinal Stabilization. Journal of Minimally Invasive Spine Surgery and Technique. 2019 Jun 30;4(1):24-8.

10. Rajasekaran S, Kanna RM, Shetty AP.Management of thoracolumbar spine trauma: An overview. Indian J Orthop. 2015;49(1):72-82.

11. Ni WF, Huang YX, Chi YL, Xu HZ, Lin Y, Wang $\mathrm{XY}$, et al. Percutaneous pedicle screw fixation for neurologic intact thoracolumbar burst fractures. $J$ Spinal Disord Tech2010;23:530-7.

12. Palmisani M, Gasbarrini A, Brodano GB, De Iure F, Cappuccio M, Boriani L, et al. Minimally invasive percutaneous fixation in the treatment of thoracic and lumbar spine fractures. Eur Spine $J$ 2009;18:71-4.

13. Wang $\mathrm{H}$, Zhou $\mathrm{Y}$, Li C, Liu J, Xiang L.Comparison of open versus percutaneous pedicle screw fixation using the sextant system in the treatment of traumatic thoracolumbar fractures. Clinical spine surgery. 2017;30(3):E239-46.

14. Wild MH, Glees M, Plieschnegger C, Wenda K. five year follow up examination after purely minimally invasive posterior stabilization of thoracolumbar fractures; A comparison of minimally invasive percutaneous and conventionally open treated patients. Arch orthopedic trauma surg, 2007; 127: 335-43.

15. Merom L, Raz N, Hamud C, Weisz I, Hanani A.Minimally invasive burst fracture fixation in the thoracolumbar region. Orthopedics 2009;32:273-8.

16. Schmidt OI, Sergej S, Victoria K, Ewald S, Ralf G. Role of early minimal-invasive spine fixation in acute thoracic and lumbar spine trauma. Indian Journal of Orthopaedics, 2007; 41(4):374-80

17. Wang B, Fan Y, Dong J, Wang H, Wang F, Liu Z, Liu H, Feng Y, Chen F, Huang Z, Chen R. A retrospective study comparing percutaneous and open pedicle screw fixation for thoracolumbar fractures with spinal injuries. Medicine. 2017;96(38) 